\title{
Synthesis and Characterization of New Copolymer Based Cinnamyl Methacrylate Monomer: Determination of Monomer Reactivity Ratio and Statistical Sequence
}

\author{
Djahida Lerari ${ }^{a b *}$ \\ ${ }^{a}$ Centre de Recherche Scientifique et Technique en Analyses Physico-chimiques - CRAPC, \\ B.P 248, 16004, Alger, Algeria \\ ${ }^{b}$ Laboratoire de Synthèse Macromoléculaire et Thio-organique Macromoléculaire, \\ Faculté de Chimie, Université des Sciences et de la Technologie Houari Boumediene, \\ B.P 32, El-alia, 16111, Bab-ezzouar, Alger, Algeria
}

Received: June 21, 2015; Revised: July 17, 2015

\begin{abstract}
Radical-initiated copolymerization of Cinnamyl methacrylate (CMA) and Ethyl methacrylate (EMA) monomers were carried out at lower conversions $(<10 \%)$ using 2,2 '-azobisisobutyronitrile (AIBN) as initiator, in 1,4-dioxane at $60{ }^{\circ} \mathrm{C}$ and nitrogen atmosphere. Structure and composition of copolymers for wide range of monomer feed were determined by Fourier Transform Infrared (FTIR) and Ultra-violet (UV) spectroscopy analysis through recorded of analytical absorption bands for monomers units. Monomer reactivity for CMA (1)-EMA (2) pair were determined by the Finneman-Ross (F-R) and Kelen- Tudos (K-T) methods. They are $\mathrm{r}_{1}=0.135$ and $\mathrm{r}_{2}=0.868$ as determined by K-T method. Parameters $Q_{1}, e_{1}$ of CMA monomer were calculated according to Alfrey-Price model. A relatively high activity of EMA was observed as compared to CMA growing radical. This result can be explained by sterical hindrance caused by chemical structure of cinnamyl pendant group in chain growth reactions.
\end{abstract}

Keywords: cinnamyl methacrylate, ethyl methacrylate, radical copolymerization, reactivity ratios

\section{Introduction}

Free radical copolymerization is a valuable tool for tailoring the properties of polymeric materials for a broad range of applications. However, the properties of obtained copolymer depend essentially on the chemical structure of the two-monomer units and their distribution in the polymer chain.

Poly (Ethyl methacrylate) (PEMA) is methacrylic ester polymer having excellent chemical resistance, high surface resistance and offers high optical transparency ${ }^{1}$. It's widely used because of its great interest in many industrial applications and various fields, such as enhancing of electrical properties of schottky diode and conductivity of batteries ${ }^{2,3}$. Also, polymers systems, containing PEMA, shown use in dental applications, drug release and cartilage repair ${ }^{4-7}$.

On the other hand, more attention is ported to cinnamic monomers derivatives and many studies were achieved for various applications. Cinnamic acid, ethyl cinnamate and cinnamaldehyde were used to modify the polystyrene in order to prepare new photosensitive polymers able to crosslinked by ultraviolet light ${ }^{8}$.

Zhang et al. ${ }^{9}$ have reported the interest of grafting cinnamic acid on poly (vinylidene fluoride) (PVDF) to improve its hydrophilicity for membrane applications. The microporous membrane prepared from this modified PVDF-cinnamic acid showed better hydrophilicity than the pure polymer. Also, cinnamic acid has widely used to incite or enhance miscibility of polymers blends initially immiscible or few miscible, such as poly (ethyl methacrylate)/ poly (styrene) $)^{10,11}$. On the

*e-mail: lerari_zinai@yahoo.fr, dj.lerari@crapc-dz.org other hand, García-Ruiz et al. ${ }^{12,13}$ have used the cinnamic carbohydrate for direct enzymatic immobilization of tyrosinase enzyme and horseradish peroxidase. Recently, Wang et al. were interested on the synthesis of ethyl cinnamate useful for food additive and cosmetic formulation ${ }^{14}$. Hu et al. have used methoxy cinnamic acid to improve the physiological indexes of the mushroom Agaricus bisporus and extend its shelf life ${ }^{15}$. Interestingly, Lee et al. ${ }^{16}$ have used 2-(cinnamoyloxy) ethyl methacrylate to synthesis new polymer nanocomposites with improved physical properties. However, Perusal of literature shows that the investigation of cinnamyl and /or cinnamic monomers derivatives has not achieved and many studies are focused on combining characteristic of this class of monomers on others polymers, by copolymerization reaction, grafting process or blending. So, knowledge of the reactivity ratios of monomers in a copolymer system is a key to predict the composition and structure of so-obtained copolymer. Estimation of the copolymer composition and determination of their reactivity ratios is a key to evaluate the application fields of the so obtained materials.

In the copolymerization of two monomers, 1 and 2, the reactivity ratios, $r_{1}$ of a monomer 1 in copolymer with monomer 2 , is defined as the ratios $\mathrm{k}_{11} / \mathrm{k}_{12}$, where $\mathrm{k}_{11}$ is the rate constant of the reaction between a growing polymer chain having 1 as its terminal radical unit and monomer 1 (homo-propagation), and $\mathrm{k}_{12}$ is the rate constant of the reaction between the same reactive chain end and monomer 2 (co-propagation) $)^{17}$. These values of $r_{1}$ and $r_{2}$, based on copolymer molar composition, can fundamentally characterize the physical properties of the new material. Spectral methods are the most widely used 
for analysis of copolymers composition and determination of reactivity ratios values.

In this paper, we present the radical copolymerization results of cinnamyl methacrylate monomer noted as CMA with ethyl methacrylate (EMA). The choice of cinnamyl group is supported by its biocompatibility and Photo-crosslinking properties. For a fundamental characterization of this new material, we report the reactivity ratios of the comonomers calculated using Finneman-Ross $(\mathrm{F}-\mathrm{R})^{18}$ and Kelen-Tudos $(\mathrm{K}-\mathrm{T})^{19}$ methods. The parameters $(Q, e)$ of the cinnamyl methacrylate were calculated according to Alfrey-Price equation ${ }^{20}$. Dyad monomer sequence distribution was also established.

\section{Experimental Part}

\subsection{Reagents}

Ethyl methacrylate (EMA) (Aldrich, 98\%), methacryloyle chloride (Aldrich, 98\%) were purified by distillation under reduced pressure before use. Cinnamyl alcohol (Aldrich, 98\%) and 2,2'-azobisisobutyronitrile (AIBN) (Aldrich, 99\%) were purified by recrystallization in heptane and methanol respectively. The organic solvents such as methanol, 1, 4-dioxane, heptane, THF, acetonitrile, triethylamine with important grade of purity, are used as received from Merck, Aldrich without further purification.

\subsection{Synthesis of monomer cinnamyl methacrylate (CMA)}

In order to underline the cinnamyl alcohol reactivity in polymerization conditions, many experiments were carried out in dioxane at $60^{\circ} \mathrm{C}$, using AIBN as initiator. The reactions were conducted 57 hours but any viscosity was observed in solution. Moreover, no polymer precipitation was obtained when adding heptane. Similar results were obtained in presence of styrene and anhydride-maleic, used as comonomers.

Indeed, the synthesis of cinnamyl derivative was carried out as follows: To a solution of cinnamyl alcohol (CA) $(30 \mathrm{~g}, 0.22 \mathrm{~mol})$ in acetonitrile $(300 \mathrm{ml})$ was added triethylamine $(20 \mathrm{~g}, 0.19 \mathrm{~mol})$, followed by an excess of methcryloyl chloride $(21 \mathrm{ml}, 0.21 \mathrm{~mol})$. The solution was stirred for 6 hours at room temperature. In order to ensure the complete conversion of hydroxyl groups, the temperature was increased at $40{ }^{\circ} \mathrm{C}$ for $1 \mathrm{~h}$. The solution was washed first with distilled water and then with saturated sodium hydrogenocarbonate solution. The organic layer was isolated and dried over magnesium sulfate, filtered off and the solvent was removed under vacuum to give the desired product: cinnamyl methacrylate, noted as CMA (Scheme 1) (Yield: 85\%). ${ }^{1} \mathrm{H}$ NMR (300 $\mathrm{MHz}, \mathrm{CDCl}_{3}$ ). $\delta: 1.1 \mathrm{ppm}$ (s, -CH3), 4.5 ppm (m, O- $\left.\mathrm{CH}_{2}-\mathrm{C}\right), 4.8 \mathrm{ppm}\left(\mathrm{m},=\mathrm{CH}_{2}\right)$, $6.2 \mathrm{ppm}(\mathrm{m},=\mathrm{CH}), 7.2 \mathrm{ppm}(\mathrm{m},-\mathrm{CH} \mathrm{Ar})$.

\subsection{Copolymerization of cinnamyl methacrylate and ethyl methacrylate monomers CMA-EMA}

In order to study the copolymerization of cinnamyl methacrylate (CMA) with ethyl methacrylate (EMA), a set of five experiments with different feed ratios (CMA:EMA) were conducted each time (10:90, 21:79, 50:50, 70:30, 90:10). An appropriate quantities of freshly distilled monomers, AIBN $(0.1 \%)$ as free radical initiator and dioxane were placed in the reactor and stirred magnetically at room temperature under inert nitrogen atmosphere for few minutes for homogenization. Then, the temperature was increased at $60{ }^{\circ} \mathrm{C}$ for 240 minutes to polymerize at low conversion as required by the reliable determination of the reactivity ratios. The reaction was stopped by cooling down the glass reactor in liquid nitrogen. The resulting copolymer was purified by precipitation in cold heptane to remove the residual monomers, followed by dissolution in THF and re-precipitation in heptane. The obtained copolymer was dried under vacuum until constant weight. The copolymer was noted as PCMAEMA (Scheme 2). For sake of comparison, the corresponding homoplymers, poly (cinnamyl methacrylate) (PCMA) and poly (ethyl methacrylate) (PEMA) were prepared in the same conditions.

\subsection{Instrumentation and characterization}

FTIR spectra of polymers with different compositions were recorded on Perkin Elmer spectrometer at $2 \mathrm{~cm}^{-1}$ resolution with 64 scans over the spectral range of $4000-400 \mathrm{~cm}^{-1}$, using the samples in powder form. The copolymer compositions were determined by UV analysis using a Lambda 650 Perkin Elmer model UV-Visible spectrophotometer. A calibration curve was constructed using poly (cinnamyl methacrylate) PCMA prepared by free radical polymerization and measuring the absorbance at $254 \mathrm{~nm}$, using spectroscopic THF as solvent.

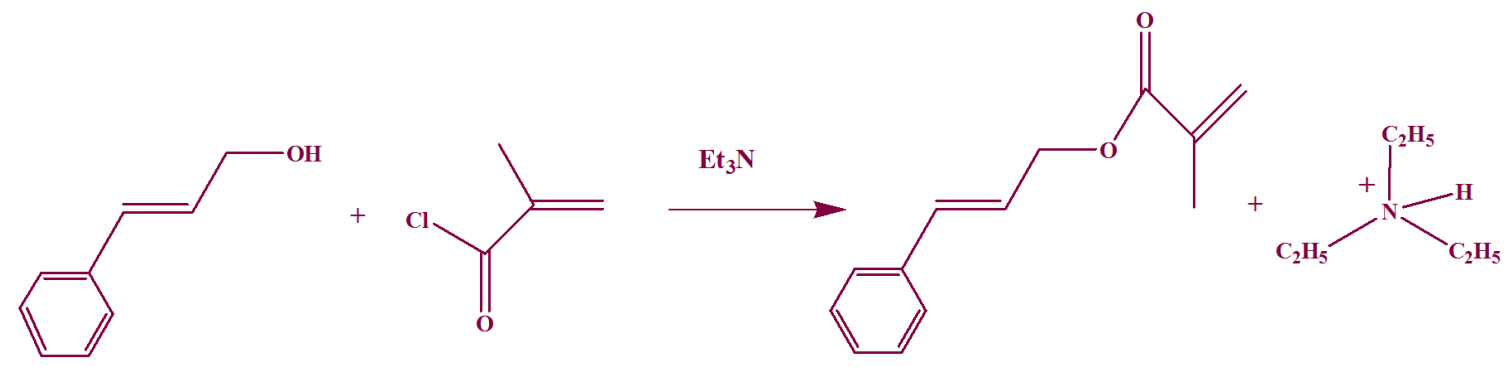




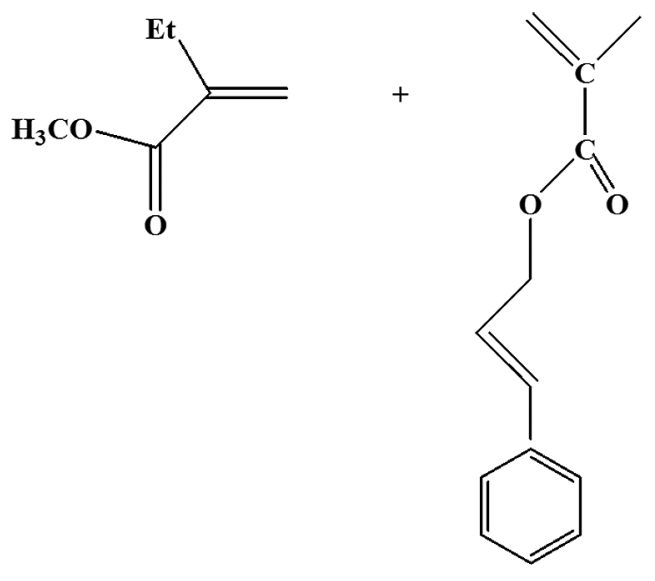

EMA
CMA

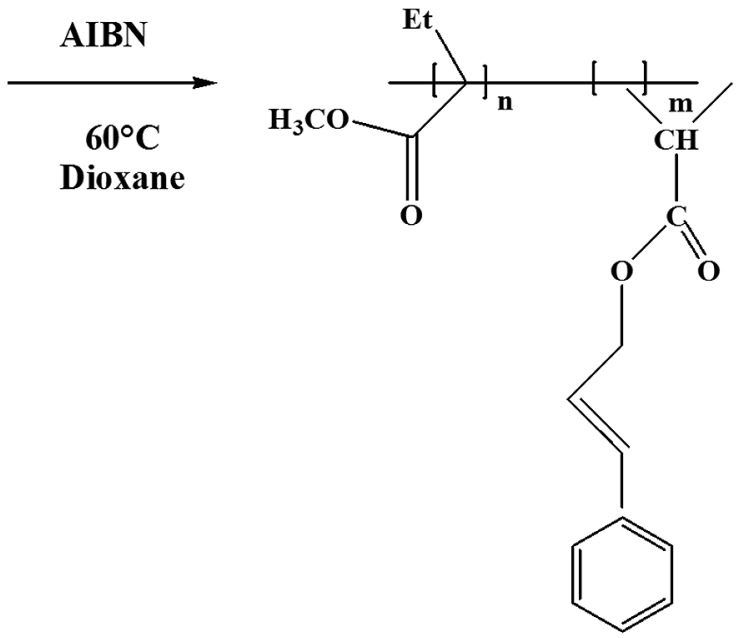

EMA-CMA copolymer

Scheme 2. General reaction for the synthesis of PCMAEMA copolymer.

\subsection{Solubility measurement}

Solubility of this new material was tested in polar and non-polar organic solvents. To a $3.0 \mathrm{ml}$ solvent, a know amount of the copolymer sample (3-6 mg) was added and kept stirred for 12 hours. The observations showed that the copolymer is soluble the polar solvents like acetone, tetrahydrofurane, chloroform, dimetylformamide, ethyl acetate. It's was insoluble in non-polar solvents such as alkanes and benzene.

\section{Results and Discussions}

\subsection{Copolymers characterization}

The free radical copolymerization of CMA with EMA was conducted under nitrogen flow, at $60^{\circ} \mathrm{C}$, using AIBN as initiator (Scheme 2). The conversion was lower than $10 \%$, satisfying the differential copolymerization evaluation. As presented in Scheme 1, the chemical structure of cinnamyl methacrylate presents two double bonds: the first in $\alpha$ position of carbonyl, the second in $\alpha$ of aromatic group. We suggest that the growing of the polymerization is available only on the double bond in $\alpha$ of $\mathrm{C}=\mathrm{O}$ function. The second bond becomes inactive, as demonstrated by the failure of the cinnamyl alcohol homopolymerization experiments, as well as its copolymerization with styrene and maleïc anhydride respectively.

Infrared spectra of the new copolymer PCMAEMA is presented in Figure 1. The peaks at $2961 \mathrm{~cm}^{-1}$ and $2876 \mathrm{~cm}^{-1}$ are assigned to the characteristic stretching vibrations of methyl groups $\left(-\mathrm{CH}_{3}\right)$ and methylene groups $\left(-\mathrm{CH}_{2}\right)$ in the copolymer. The strong absorption peak at $1730 \mathrm{~cm}^{-1}$ is assigned to the characterization peak of carbonyl ester group $(\mathrm{C}=\mathrm{O})$ of monomers CMA and EMA units of the copolymer. Additionally, the absorption peaks at $3059 \mathrm{~cm}^{-1}$ and $3026 \mathrm{~cm}^{-1}$ are attributed to the $\mathrm{C}-\mathrm{H}$ stretching vibrations of the phenyl ring in cinnamyl group. The absorption peaks at $1600 \mathrm{~cm}^{-1}$

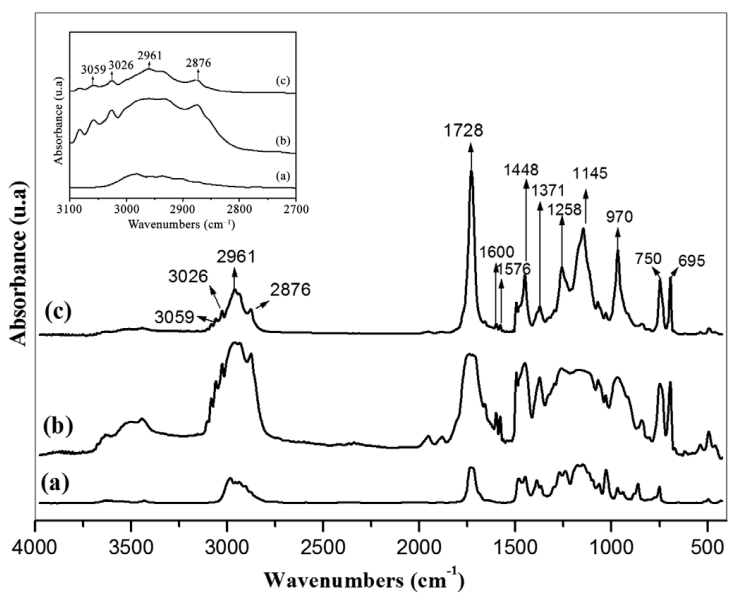

Figure 1. FTIR spectra of PEMA (a), PCMA (b) and PCMAEMA at 50:50 composition in the feed (c).

and $1576 \mathrm{~cm}^{-1}$ in both spectra of (b) and (c) correspond to the stretching vibrations of phenyl ring and $\mathrm{C}=\mathrm{C}$ stretching modes, which are the characters of cinnamyl group. The peaks at $750 \mathrm{~cm}^{-1}$ and $695 \mathrm{~cm}^{-1}$ in both spectra of (b) and (c) are attributed to the deformation vibration of $\mathrm{C}-\mathrm{H}$ in phenyl ring.

Also, the peaks at $1448 \mathrm{~cm}^{-1}, 1371 \mathrm{~cm}^{-1}, 1258 \mathrm{~cm}^{-1}$ and $1145 \mathrm{~cm}^{-1}$ are due to symmetric and asymmetric deformation vibrations of alkyls $\left(-\mathrm{CH}_{2},-\mathrm{CH}_{3}\right)$ groups of both monomers. The peak at $970 \mathrm{~cm}^{-1}$ is attributed to ketone function $(\mathrm{C}-\mathrm{O})$. However, the copolymers composition was monitored by ultra-violet spectroscopy on the basis of Beer-Lamber law. The absorbance versus concentration curve of poly (cinnamyl methacrylate) (PCMA) (coefficient extinction $\left.\varepsilon=60,736 \mathrm{~cm}^{-1} \cdot \mathrm{g}^{-1} .1\right)$ and absorption maxima of different copolymers PCMAEMA at $254 \mathrm{~nm}$ are illustrated in Figures 2a, $2 \mathrm{~b}$. The composition of copolymers samples $\left(\mathrm{m}_{1}, \mathrm{~m}_{2}\right)$ obtained 


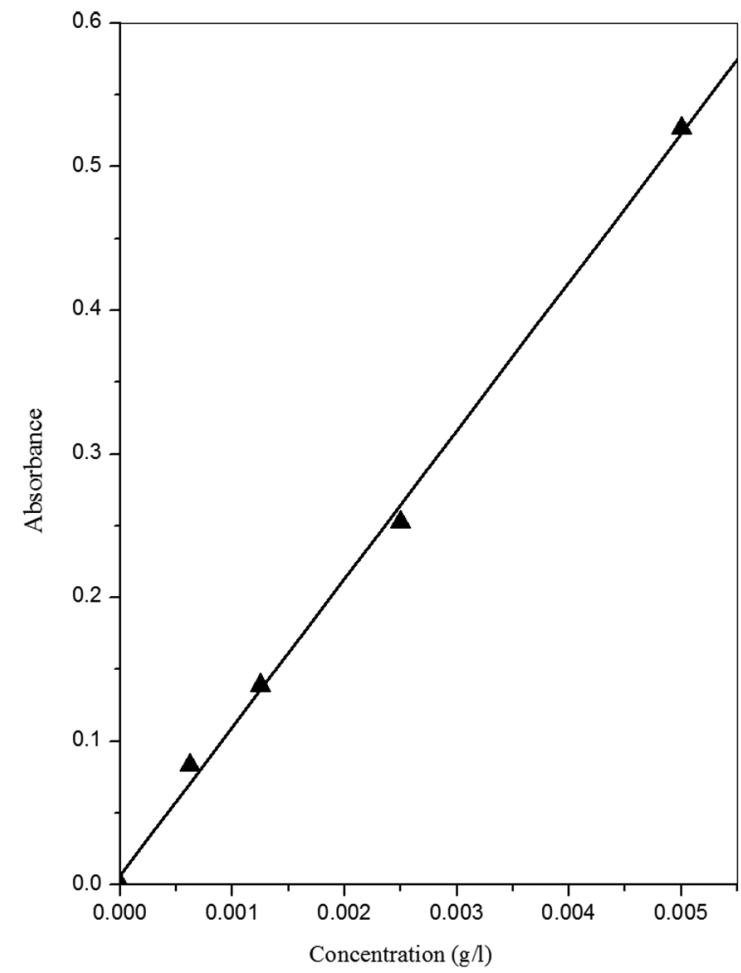

(a)

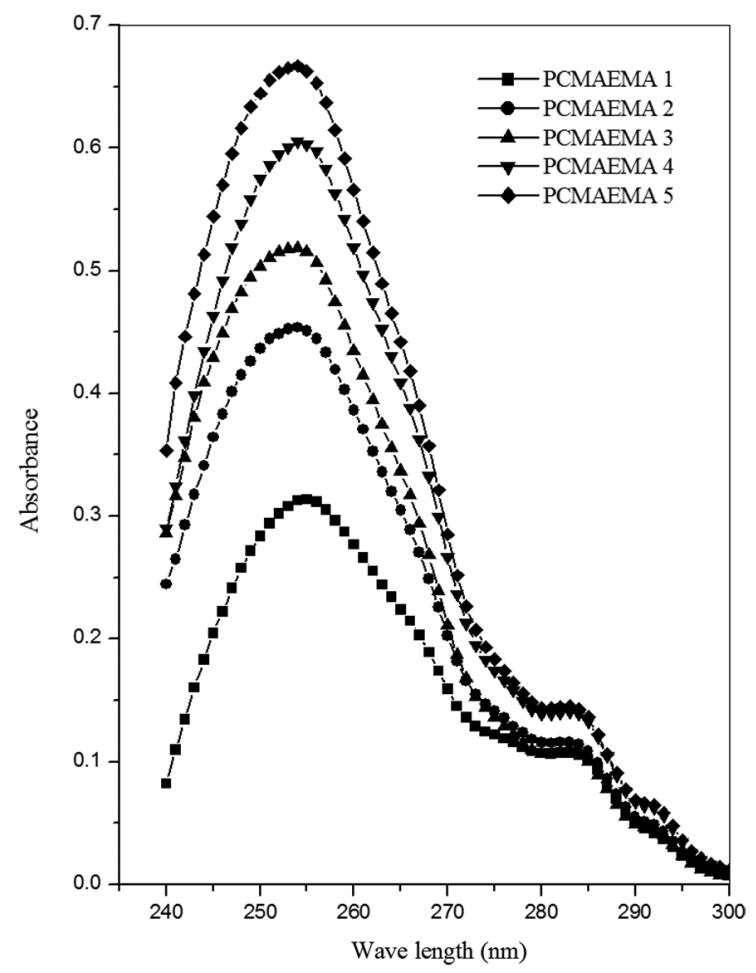

(b)

Figure 2. (a) Absorption maxima of poly (cinnamyl methacrylate) at different concentrations (b) UV visible spectra of different PCMAEMA copolymers in spectroscopic THF $\left([\mathrm{c}]=0.01 \mathrm{~g} \cdot \mathrm{l}^{-1}\right)$.

from various feed ratios of CMA and EMA $\left(\mathrm{M}_{1}, \mathrm{M}_{2}\right)$ are summarized in Table 1. The mole fraction of CMA $\left(\mathrm{m}_{1}\right)$ in the copolymer PCMAEMA is equal to that in the feed $\left(\mathrm{M}_{1}\right)$ at a composition 21:79 (CMA: EMA). Figure 3 shows the molar fraction of CMA in the copolymers versus the molar fraction in the comonomer feed. In all the cases, incorporation of cinnamyl methacrylate into the copolymer is lower than that of ethyl methacrylate, being obviously more reactive than CMA. However, the percentage of cinnamyl methacrylate monomer involved in the copolymerization is less than the percentage of the monomer in the feed (Figure $3(\bullet)$ ). On the other words the conversion of CMA monomer remains below the ideality (Figure 3(๘)). This result was confirmed by calculating the reactivity ratios of the copolymer.

\subsection{Monomer reactivity ratios and statistical distribution}

It's clear that the copolymer composition depends on the monomer feed composition and the relative monomers reactivity in the synthesis conditions such as temperature, solvent and initiator. Copolymerization reactivity ratios of CMA and EMA in the copolymer were determined according to the low conversion reported by Finneman-Ross (F-R) and Kelen-Tudos (K-T) graphical methods based on ultra-violet spectroscopy values ${ }^{18,19}$. According to the Finneman-Ross method (F-R), the monomer reactivity ratios can be obtained by the following equation:

$G=H r_{1}-r_{2}$

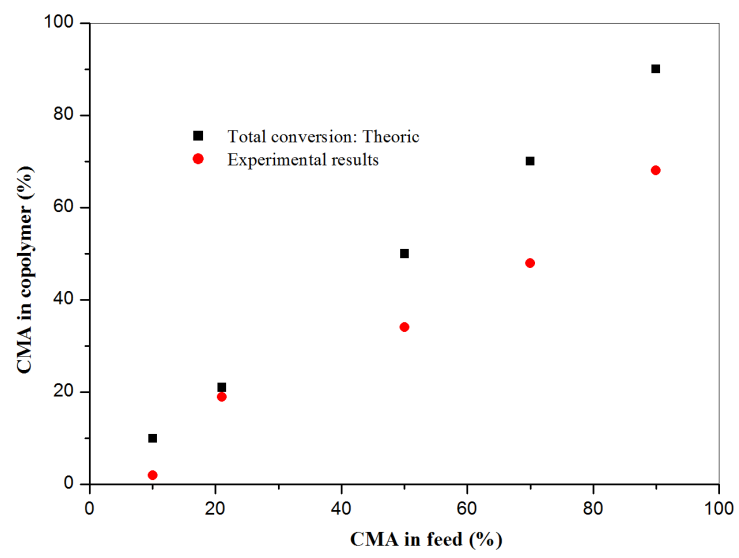

Figure 3. Composition curves for the copolymerization of CMA with EMA.

Where: $r_{1}$ and $r_{2}$ are the reactivity ratios relating to the monomers CMA and EMA, respectively. The F-R parameters reported in Table 1 are defined as:

$G=X(Y-1) / Y$ and $H=X^{2} / Y$

With:

$X=M_{1} / M_{2}, Y=m_{1} / m_{2}$

$\mathrm{M}_{1}$ and $\mathrm{M}_{2}$ are the monomer molar composition in feed and $m_{1}, m_{2}$ the copolymer molar composition. The reactivity ratios are determined according to the plots of the $\mathrm{G}$ versus 
Table 1. F-R and K-T parameters for PCMAEMA copolymers.

\begin{tabular}{|c|c|c|c|c|c|c|c|c|c|c|}
\hline \multirow[b]{2}{*}{ Entry } & \multicolumn{2}{|c|}{ Monomer } & \multicolumn{2}{|c|}{ Copolymer } & \multicolumn{4}{|c|}{ Parameters of $F-R$} & \multicolumn{2}{|c|}{ Parameters of K-T } \\
\hline & $\begin{array}{c}\text { CMA } \\
\left(M_{1}\right)\end{array}$ & $\begin{array}{c}\text { EMA } \\
\left(\mathbf{M}_{2}\right) \\
\end{array}$ & $\begin{array}{c}\text { CMA } \\
\left(m_{1}\right)\end{array}$ & $\begin{array}{c}\text { EMA } \\
\left(\mathbf{m}_{2}\right)\end{array}$ & $\mathbf{X} \mathbf{M}_{1} / \mathbf{M}_{2}$ & $\begin{array}{c}\mathbf{Y} \\
\mathrm{m}_{1} / \mathrm{m}_{2}\end{array}$ & $\begin{array}{c}G \\
\mathbf{x}(\mathbf{y}-1) / y\end{array}$ & $\begin{array}{c}\mathbf{H} \\
\mathbf{x}^{2} / \mathbf{y}\end{array}$ & $\underset{\mathbf{G} /(\boldsymbol{\alpha}+\mathbf{H})}{\boldsymbol{\eta}}$ & $\begin{array}{c}\Xi \\
\mathbf{H} /(\mathbf{A}+\mathbf{H})\end{array}$ \\
\hline PCMAEMA 1 & 10 & 90 & 02 & 98 & 0.111 & 2.128 & 4.770 & 38.067 & 0.117 & 0.933 \\
\hline PCMAEMA 2 & 21 & 79 & 19 & 81 & 0.266 & 0.926 & -0.186 & 5.878 & -0.022 & 0.683 \\
\hline PCMAEMA 3 & 50 & 50 & 34 & 66 & 2.333 & 0.598 & -0.673 & 1.673 & -0.153 & 0.380 \\
\hline PCMAEMA 4 & 70 & 30 & 48 & 52 & 0.266 & 0.249 & -0.804 & 0.284 & -0.266 & 0.094 \\
\hline PCMAEMA 5 & 90 & 10 & 68 & 32 & 9 & 0.063 & -1.655 & 0.196 & -0.565 & 0.067 \\
\hline
\end{tabular}

H values as shown in Figure 4. On the other hand, reactivity ratios of CMA and EMA were determined by the application of Kelen-Tudos (K-T) method according to Equation 4:

$\eta=\left(r_{1}+r_{2} / \alpha\right) \xi-r_{2} / \alpha$

Where:

$\eta=G /(\alpha+H), \xi=H /(\alpha+H)$ and $\alpha=\left(H_{\max } \cdot H_{\min }\right)^{1 / 2}$

$\mathrm{H}_{\max }$ and $\mathrm{H}_{\min }$ are the maximum and the minimum $\mathrm{H}$ values, respectively from the series of measurements. The values of $\eta$ for $\xi=0$ and $\xi=1$ are used to calculate the reactivity ratios according to the Equation 5. K-T parameters are illustrated in Table 1. A K-T plot of $\eta$ vs. $\xi$ is presented in Figure 5. The plots were linear in all cases and for all graphical methods, thus indicating that this copolymerization follows the conventional copolymerization kinetics. The values obtained by the F-R and K-T methods are in good agreement (Table 2). PMCIEMA copolymer undergoes statistical enchainment with more EMA units. As seen from these values, homoplymerization of EMA is favored over that of CMA. In other words, EMA is the more active comonomer in copolymerization with CMA. This result is an agreement with reactivity ratios values reported by Demirelli et al, relating to 3, 4-Dichlorobenzyl methacrylate-ethyl methacrylate copolymer $^{21}$. The low reactivity of the monomer CMA towards its own radical can be attributed to the size of the substituted cinnamyl pendant group which creates a sterical hindrance and decreases consequently the probability that the radical cinnamyl methacrylate $(\mathrm{CMA} \bullet)$ is added on a growing macroradical of $\sim \mathrm{CMA} \bullet$. This observation is accented by the great reactivity of the smaller ethyl methacrylate radical (EMA•). The copolymer will have statistical arrangement units in which EMA will tend to predominate. The product $r_{1} r_{2}<1$ suggests a tendency towards a random distribution of monomers units. The copolymer chains remain rich on EMA sequences. This result is similar to that obtained by Pekel et al. for the free radical copolymerization of $\mathrm{N}$-vinylimidazole and ethyl methacrylate 22 .

The parameters of specific activity $\left(Q_{1}\right)$ and polarity $\left(e_{1}\right)$ for this new monomer (CMA) were calculated according to Alfrey and Price equation, on suggesting that the parameters $e$ of the monomer and the corresponding radical are equal $\left(e_{1}=e_{l}^{*}\right)^{18}$ (Equations 6 and 7).

$r_{l}=\left(Q_{1} / Q_{2}\right) \exp \left[-e_{1}\left(e_{1}-e_{2}\right)\right]$

$r_{2}=\left(Q_{2} / Q_{1}\right) \exp \left[-e_{2}\left(e_{2}-e_{1}\right)\right]$
Table 2. Monomer reactivity ratios for PCMAEMA copolymer by F-R and K-T methods.

\begin{tabular}{cccc}
\hline Method & $\mathbf{r}_{1}$ & $\mathbf{r}_{2}$ & $\mathbf{r}_{1 .} \mathbf{r}_{2}$ \\
\hline F-R & 0.149 & 0.938 & 0.139 \\
K-T & 0.135 & 0.868 & 0.117 \\
\hline
\end{tabular}

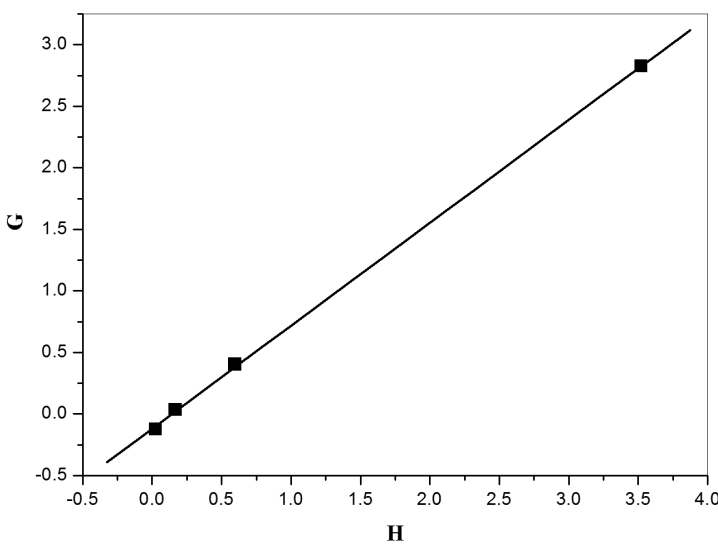

Figure 4. Finneman-Ross plot of G vs. F.

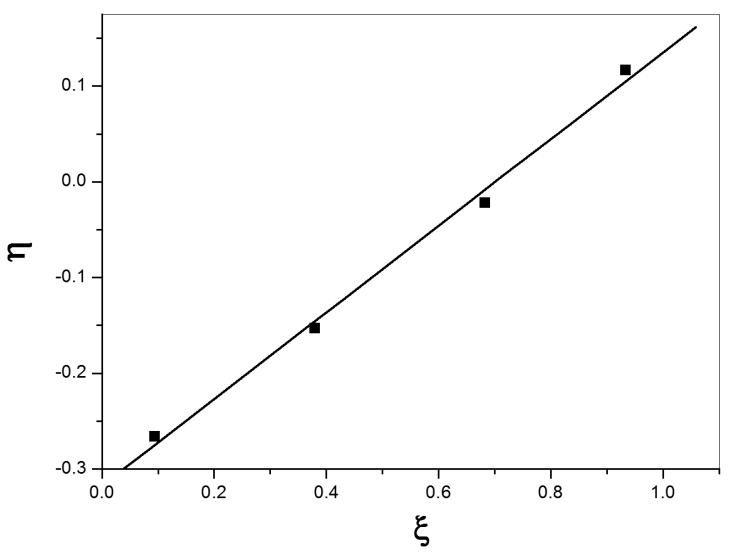

Figure 5. Kelen-Tudos plot of $\eta$ vs. $\xi$.

Know of $Q$ and $e$ of EMA monomer $\left(Q_{2}=0.56, e_{2}=0.17\right)^{22,23}$, the values of CMA are calculated: $Q_{1}=0.826, e_{1}=1.603$. These results correlate with the energy localization and pi-electron density of CMA double bond. However, in the copolymerization reaction, activity of $\sim$ EMA $\bullet$ growing radical increases, and therefore more easily adds to EMA 
Table 3. Structural data for the statistical copolymers.

\begin{tabular}{cccccc}
\hline Entry & $\mathbf{f}_{\mathbf{1 1}} \mathbf{a}^{\mathbf{a}}$ & $\mathbf{f}_{\mathbf{2 2}} \mathbf{a}^{\mathbf{a}}$ & $\mathbf{f}_{\mathbf{1 2}} \mathbf{a}^{\mathbf{a}}$ & $\boldsymbol{\mu}_{\text {CMA }}{ }^{\mathbf{b}}$ & $\boldsymbol{\mu}_{\text {EMA }}{ }^{\mathbf{b}}$ \\
\hline PCMAEMA 1 & 0.002 & 0.962 & 0.036 & 1.016 & 9.127 \\
PCMAEMA 2 & 0.023 & 0.643 & 0.333 & 1.038 & 4.397 \\
PCMAEMA 3 & 0.054 & 0.374 & 0.571 & 1.142 & 1.903 \\
PCMAEMA 4 & 0.117 & 0.157 & 0.726 & 1.331 & 1.387 \\
PCMAEMA 5 & 0.375 & 0.015 & 0.610 & 2.278 & 1.100 \\
\hline
\end{tabular}

adefined in Equations 8-10. bdefined in Equations 11,12.

monomer then that to CMA monomer. In order to illustrate the reactivity of each monomer, the statistical distribution of the dyad monomers sequences CMA-CMA, EMA-EMA and CMA-EMA were calculated according to Igarashi method ${ }^{24,25}$ based on Equations 8-10:

$$
\begin{aligned}
& f_{11}=\varphi_{C M A}-\frac{2 \varphi_{C M A}\left(1-\varphi_{C M A}\right)}{1+\sqrt{\left[\left(2 \varphi_{C M A}-1\right)^{2}+4 r_{C M A} \cdot r_{E M A} \cdot \varphi_{E M A}\left(1-\varphi_{C M A}\right)\right]}} \\
& f_{22}=1-\varphi_{C M A}-\frac{2 \varphi_{C M A}\left(1-\varphi_{C M A}\right)}{1+\sqrt{\left[\left(2 \varphi_{C M A}-1\right)^{2}+4 r_{C M A} \cdot r_{E M A} \cdot \varphi_{E M A}\left(1-\varphi_{C M A}\right)\right]}} \\
& f_{12}=\frac{4 \varphi_{C M A}\left(1-\varphi_{C M A}\right)}{1+\sqrt{\left[\left(2 \varphi_{C M A}-1\right)^{2}+4 r_{C M A} \cdot r_{E M A} \cdot \varphi_{E M A}\left(1-\varphi_{C M A}\right)\right]}}
\end{aligned}
$$

Where:

$f_{11}, f_{22}, f_{12}$ : moles fractions of the CMA-CMA, EMA-EMA and CMA-EMA dyads in the copolymer respectively. $\varphi_{\mathrm{CMA}}$ : The CMA mole fraction in the copolymer.

Also, mean sequence length $\mu_{\mathrm{CMA}}$ and $\mu_{\mathrm{EMA}}$ were calculated using the Equations 11 and 12 respectively ${ }^{24,26,27}$. The data are summarized in Table 3.

$$
\begin{aligned}
& \mu_{C M A}=1+r_{C M A}\left(M_{C M A} / M_{E M A}\right) \\
& \mu_{E M A}=1+r_{E M A}\left(M_{E M A} / M_{C M A}\right)
\end{aligned}
$$

Figure 6 displays the variation of the dyad fractions with the EMA mole fraction in the copolymer. It is clear that the mole fraction of the CMA-CMA dyad is the minority component for almost all copolymer compositions. It achieves a maximal value of 0.4 for a polymer composition of 70 on CMA. However, the mole fraction of the CMA-EMA dyad is predominant for that composition. On contrary, the mole fraction of the EMA-EMA dyads increases and becomes very important. This a manifestation of the difference of monomers reactivity, as reflected at the reactivity ratios values for the corresponding monomers.

\section{References}

1. Reiter J, Krejza O and Sedlarikova M. Electrochromic devices employing methacrylate-based polymer electrolytes. Solar Energy Materials and Solar Cells. 2009; 93(2):249-254. http:// dx.doi.org/10.1016/j.solmat.2008.10.010.

2. Reddy VR, Umapathi A and Rao LD. Effect of annealing on the electronic parameters of $\mathrm{Au} /$ poly(ethylmethacrylate)/nInP Schottky diode with organic interlayer. Current Applied Physics. 2013; 13(8):1604-1610. http://dx.doi.org/10.1016/j. cap.2013.06.001.

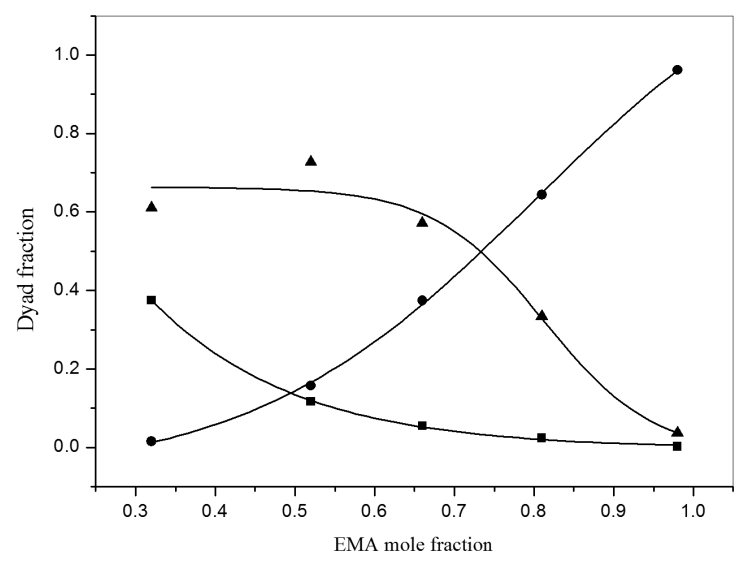

Figure 6. Dyad monomer sequence fractions versus EMA moles fraction for the CMA-CMA (•), EMA-EMA (•) and CMA-EMA $(\boldsymbol{\Delta})$ dyads.

\section{Conclusion}

The CMA and EMA monomers have been selected to investigate their free-radical copolymerization behavior. By applying Finneman-Ross and Kelen-Tudos methods to the copolymerization data obtained from UV spectroscopy analysis of copolymers quenched at low conversion, the reactivity ratios of cinnamyl methacrylate (1) and ethyl methacrylate (2) were found to be $r_{1}=0.142$ and $r_{2}=0.903$ respectively. Relatively low activity of CMA growing radical was explained by the size of the cinnamyl pendant group, conducting on formation of random copolymers. The result is an agreement with the dyads statistical distribution in the copolymer.

It appears essential to promote other copolymers based- cinnamyl methacrylate to propose applications of this new synthesized material. Such an approach is under current investigation by combining polymerization/grafting reactions and blending of PCMAEMA with other copolymers.

3. Aravindan $\mathrm{V}$, Lakshmi C and Vickraman P. Investigations on $\mathrm{Na}+$ ion conducting polyvinylidenefluoride-co-hexafluoropropylene/ poly ethylmethacrylate blend polymer electrolytes. Current Applied Physics. 2009; 9(5):1106-1111. http://dx.doi.org/10.1016/j. cap.2008.12.009.

4. Pearson GJ, Picton DCA, Braden M and Longman C. The effects of two temporary crown materials on the dental pulp of monkeys (Macaca fascicularis). International Endodontic Journal. 1986; 19(3):121-124. http://dx.doi.org/10.1111/j.1365-2591.1986. tb00464.x. PMid:3460966. 
5. Di Silvio L, Kayser MV and Downes S. Validation and optimization of a polymer system for potential use as a controlled drugdelivery system. Clinical Materials. 1994; 16(2):91-98. http:// dx.doi.org/10.1016/0267-6605(94)90102-3. PMid:10147328.

6. Downes S, Archer RS, Kayser MV, Patel MP and Braden M. The regeneration of articular cartilage using a new polymer system. Journal of Materials Science. 1994:88-95.

7. Hutcheon GA, Messiou C, Wyre RM, Davies MC and Downes S. Water absorption and surface properties of novel poly(ethylmethacrylate) polymer systems for use in bone and cartilage repair. Biomaterials. 2001; 22(7):667-676. http:// dx.doi.org/10.1016/S0142-9612(00)00229-5. PMid:11246960.

8. Farrall J. Pareparation of photosensitive polymers containing pendant cinnamic acid, ethyl cinnamate or cinnamaldehyde groups by chemical modification of polystyrene. Polymer Bulletin. 1984; 11(2):191-194. http://dx.doi.org/10.1007/ BF00258029.

9. Zhang X, Meng H and Di Y. Synthesis and characterization of cinnamic acid-grafted poly(Vinylidene Fluoride) microporous membranes. Energy Procedia. 2012; 17:1850-1857. http:// dx.doi.org/10.1016/j.egypro.2012.02.322.

10. Bouslah N, Haddadine N, Bendiabdallah D and Amrani F. Study of the miscibility of poly(ethyl methacrylate- co -4-vinylpyridine)/ poly(styrene- co -cinnamic acid) blends. Polymer Bulletin. 1999; 42(6):701-708. http://dx.doi.org/10.1007/s002890050522.

11. Bouslah N and Amrani F. Miscible blends of styrene-cinnamic acid copolymers with poly(ethyl methacrylate). Polymer International. 2001; 50(12):1384-1390. http://dx.doi.org/10.1002/ pi.746.

12. García-Ruiz PE, Marín-Zamora ME, Rojas-Melgarejo F and García-Cánovas F. Direct immobilization of tyrosinase enzyme from natural mushrooms (Agaricus bisporus) on D-sorbitol cinnamic ester. Journal of Biotechnology. 2006; 126(3):295-303. http://dx.doi.org/10.1016/j.jbiotec.2006.04.024. PMid:16730834.

13. García-Ruiz PE, Rojas-Melgarejo F, Rodríguez-López JN and García-Cánovas F. Immobilization of horseradish peroxidase on cinnamic carbohydrate esters. Process Biochemistry. 2004; 39(11):1455-1464. http://dx.doi.org/10.1016/S00329592(03)00276-0.

14. Wang Y, Zhang DH, Zhang JY, Chen N and Zhi GY. High-yield synthesis of bioactive ethyl cinnamate by enzymatic esterification of cinnamic acid. Food Chemistry. 2016; 190:629-633. http:// dx.doi.org/10.1016/j.foodchem.2015.06.017. PMid:26213020.

15. Hu YH, Chen CM, Xu L, Cui Y, Yu XY, Gao HJ et al. Postharvest application of 4-methoxy cinnamic acid for extending the shelf life of mushroom (Agaricus bisporus). Postharvest Biology and Technology. 2015; 104:33-41. http://dx.doi.org/10.1016/j. postharvbio.2015.03.007.
16. Lee Y, Kiran Kumar ABV and Thangadurai TD. Poly [2-(cinnamoyloxy)ethyl methacrylate-co-octamethacryl-POSS] nanocomposites: Synthesis and properties. Reactive \& Functional Polymers. 2013; 73(9):1175-1179. http://dx.doi.org/10.1016/j. reactfunctpolym.2013.05.010.

17. Ydens I, Degée P, Haddleton DM and Dubois P. Reactivity ratios in conventional and nickel-mediated radical copolymerization of methyl methacrylate and functionalized methacrylate monomers. European Polymer Journal. 2005; 41(10):2255-2263. http:// dx.doi.org/10.1016/j.eurpolymj.2005.04.012.

18. Fineman M and Ross SD. Linear method for determining monomer reactivity ratios in copolymerization. Journal of Polymer Science. Polymer Physics Edition. 1950; 5:259-265.

19. Kelen I and Tüdõs F. Analysis of the linear methods for determining copolymerization reactivity Ratios. I. A new improved linear graphic method. Journal of Macromolecular Science: Part A - Chemistry. 1975; 9:1-27. http://dx.doi. org/10.1080/00222337508068644.

20. Alfrey T and Price CC. Relative reactivities in vinyl copolymerization. Journal of Polymer Science. Polymer Physics Edition. 1947; 2:101-106.

21. Demirellia K, Kaya I and Coşkun M. 3, 4-Dichlorobenzyl methacrylate and ethyl methacrylate system: monomer reactivity ratios and determination of thermodynamic properties at infinite dilution by using inverse gas chromatography. Polymer. 2001; 42:5181-5188. http://dx.doi.org/10.1016/S0032-3861(01)000192.

22. Pekel N, Şahiner N, Güven O and Rzaev ZMO. Synthesis and characterization of $\mathrm{N}$-vinylimidazole-ethyl methacrylate copolymers and determination of monomer reactivity ratios. European Polymer Journal. 2001; 37(12):2443-2451. http:// dx.doi.org/10.1016/S0014-3057(01)00124-0.

23. Ham GE. Copolymerization. New York: Wiley Interscience; 1964.

24. Igarashi S. Representation of composition and blockiness of the copolymer by a triangular coordinate system. Journal of Polymer Science Part C: Polymer Letters. 1963; 1(7):359-362. http://dx.doi.org/10.1002/pol.1963.110010706.

25. Driva P, Bexis P and Pitsikalis M. Radical copolymerization of 2-vinyl pyridine and oligo(ethylene glycol) methyl ether methacrylates: Monomer reactivity ratios and thermal properties. European Polymer Journal. 2011; 47(4):762-771. http://dx.doi. org/10.1016/j.eurpolymj.2010.09.032.

26. Elias HG. Macromolecules. New York: Plenum Press; 1971. v. 2. 761 p. Chapter 22.

27. Manju M, Veeraiah MK, Prasannakumar S, Gowda NMM, Sherigara BS. Synthesis and Characterization of Copolymers of Methyl Methacrylate and 2-Ethoxyethyl Methacrylate. American Journal of Polymer Science. 2012; 2(3):22-27. 